OPEN ACCESS

Edited by:

Harry W. Schroeder,

University of Alabama

at Birmingham, United States

Reviewed by:

Kay L. Medina,

Mayo Clinic, United States Yoshiteru Sasaki,

Kyoto University, Japan

*Correspondence: Stephen Malin

stephen.malin@ki.se

Specialty section: This article was submitted to B Cell Biology,

a section of the journal

Frontiers in Immunology

Received: 12 June 2017 Accepted: 09 October 2017 Published: 24 October 2017

Citation:

Habir K, Aeinehband S, Wermeling F and Malin S (2017) A Role for the

Transcription Factor Arid3a in Mouse

B2 Lymphocyte Expansion and

Peritoneal B1a Generation.

Front. Immunol. 8:1387.

doi: 10.3389/fimmu.2017.01387

\section{A Role for the Transcription Factor Arid3a in Mouse B2 Lymphocyte Expansion and Peritoneal B1a Generation}

\author{
Katrin Habir, Shahin Aeinehband, Fredrik Wermeling and Stephen Malin* \\ Department of Medicine, Center for Molecular Medicine, Karolinska University Hospital, Karolinska Institutet, Stockholm, \\ Sweden
}

The initiation, commitment, and terminal differentiation of the B cell lineage is stringently controlled by the coordinated action of various transcription factors. Among these, Arid3a has previously been implicated in regulating early B lymphopoiesis, humoral immune responses to phosphocholine, and furthermore to promote the B1 over the B2 cell lineage. We have now interrogated the function of Arid3a in the adult mouse using conditional mutagenesis. We demonstrate that loss of Arid3a does not affect early B cell development or lineage commitment but rather loss of this transcription factor results in a broad expansion of bone marrow $B$ lymphopoiesis in a manner that reflects its developmental expression pattern. Furthermore, loss of Arid3a resulted in expanded splenic B cell numbers with the exception of the B1 lineage that was maintained at normal numbers. However, B1a lymphoyctes were reduced in the peritoneal cavity. In addition, antibody responses to phosphocholine were attenuated in the absence of Arid3a. Hence, functional Arid3a is required in mature B cells for specific immune responses and for generating normal numbers of $B$ cells in a subset dependent manner.

\section{Keywords: Arid3a, B cell development, spleen, bone marrow, antibody formation}

\section{INTRODUCTION}

B lymphocytes form the humoral arm of adaptive immunity through their unique ability to construct and secrete antibodies. The B cell lineage can be broadly separated into the B1 and B2 lineages through the combination of surface markers, ontogeny, physiological location, and specificity for antigen (1). The microRNA Let-7 and RNA-binding protein LIN28b have a critical role in specifying this B1 versus B2 lymphocyte lineage (2).

Arid $3 a$ was identified through its ability to bind and transcriptionally regulate the immunoglobulin heavy chain gene $(3,4)$ and has been recently claimed to be a critical downstream target of the Let-7/LIN28b axis (5). There have been conflicting reports on the function of Arid3a within the B cell lineage. Germline deletion of Arid3a leads to multiple defects in both hematopoietic progenitors and bone marrow resident B cells, including B1 cells (6). Additional approaches using knockdown or overexpression of Arid3a followed by transplantation into lymphopenic hosts has led to the hypothesis that Arid3a is required for specifying the B1 cell fate over the B2 cell fate (5). Conversely, lymphocyte-specific deletion of Arid $3 a$ through RAG-deficient blastocyst complementation experiments did not reveal any significant differences in mature B cell development 
(6). Similarly, transgenic overexpression of a dominant-negative ARID3A protein had no effect on bone marrow B cell development or on the B1 versus B2 lineage in the peritoneum (7).

To circumvent the embryonic lethality of Arid3a germline deleted mice, we have created a conditional loss-of-function allele and combined this with B cell-specific Cre-mediated deletion. Comprehensive analysis of the $\mathrm{B}$ cell compartment in these mice revealed expansion of the bone marrow pro- $\mathrm{B}$, pre- $\mathrm{B}$, immature and recirculating stages of $\mathrm{B}$ cell development upon Arid $3 a$ deletion, as well as defects in humoral immunity. In notable contrast, adult $\mathrm{B} 1$ cells are reduced, but only in the peritoneal cavity, following the loss of Arid3a.

\section{RESULTS}

\section{Conditional Loss of Arid3a and B Cell Development}

The expression pattern of the transcription factor Arid $3 a$ is believed to be largely restricted to the $\mathrm{B}$ cell lineage within the hematopoietic system (8). We first determined the pattern of Arid3a expression by examining the ImmGen database (9) and could confirm that Arid $3 a$ is restricted to $\mathrm{B}$ cells with the exception of prominent expression also within granulocytes. Surprisingly, Arid3a was not strongly expressed in hematopoietic stem cells or progenitors, but instead showed upregulation within B cell progenitors resident in the bone marrow (Figure 1A). Specifically, Arid3a expression was upregulated through successive maturation steps from the pro-B to immature B cell stages. Interestingly, B1 cells did show only moderately increased expression of Arid3a.

We next wished to interrogate the in vivo function of Arid3a by genetic loss-of-function analysis. We generated a floxed allele of Arid3a by first removing the Lacz/Neo cassette of Arid3 $a^{\text {tmIa(KOMP)Wtsi }}$ by FLPE-mediated recombination to create an allele that contains Loxp sites flanking exon 4 (Figure S1A in Supplementary Material). This encodes for amino acids 237-261 that are crucial for Arid3a DNA binding (4), and additionally loss of exon 4 will result in an out of frame allele and a nonsense protein. We then crossed this floxed allele with the B cell-specific Cre line $C d 79 a^{C r e}\left(M b 1^{C r e}\right)$, which initiates deletion at the transition from the common lymphoid progenitor to the pro-B cell stage of development (10). We therefore created littermate cohorts of Arid $3 a^{f l / f l}$ (herein referred to as control mice), Arid $3 a^{f l /+}$ $C d 79 a^{C r e /+}$ (herein referred to as heterozygous mice), and Arid $3 a^{f l}$ ${ }^{f l} \mathrm{Cd} 79 a^{\mathrm{Cre} /+}$ (herein referred to as homozygous mice) and analyzed the B cell compartment in the bone marrow of these mice at 4-6 weeks of age. We found that loss of Arid $3 a$ influenced the relative abundance of the $\mathrm{B} 1$ (defined $\mathrm{B} 220^{\mathrm{lo}} \mathrm{CD} 19^{+}$) populations in the bone marrow, with approximate 1.7-fold decreases in B1 cells in heterozygous versus control mice $(p=0.0047)$ and 1.8fold decreases in homozygous versus control mice $(p=0.0006)$. In contrast, the $\mathrm{B} 2$ population (defined $\mathrm{B} 220^{+} \mathrm{CD} 19^{+}$) was expanded 1.7-fold in heterozygous versus control $(p<0.0001)$ and 2-fold increased in the homozygous versus control cohorts $(p=0.0006)$ (Figure 1B). We next determined which stage of $\mathrm{B}$ cell development was responsible for this increase in B2 cells. The first committed pro-B stage of B cell development (defined
$\left.\mathrm{B} 220^{+} \mathrm{CD}_{19}{ }^{+} \mathrm{IgM}^{-} \mathrm{IgD}^{-} \mathrm{c}-\mathrm{Kit}^{+} \mathrm{CD} 25^{-}\right)$was increased 2.5 -fold in homozygous mice upon loss of Arid3a ( $p=0.038$ ). Later stages of $\mathrm{B}$ cell development were also expanded. The pre- $\mathrm{B}$ population (defined $\mathrm{B} 220^{+} \mathrm{CD} 19^{+} \mathrm{IgM}^{-} \mathrm{IgD}^{-} \mathrm{c}-\mathrm{Kit}^{-} \mathrm{CD} 25^{+}$) including the large pre-B and small and pre-B subpopulations increased approximately 1.9-fold in both heterozygous and homozygous mice (control versus heterozygous $p=0.0001$ : control versus homozygous $p<0.0001$ ). Immature-B (defined $\mathrm{B} 220^{+} \mathrm{CD} 19^{+} \mathrm{Ig}$ $\mathrm{M}^{+} \mathrm{IgD}^{-}$) were increased 2-fold in the homozygous versus control mice $(p=0.038)$, whereas recirculating $\mathrm{B}$ cells (defined $\mathrm{B} 220^{+} \mathrm{CD}$ $\left.19^{+} \operatorname{IgM}^{-} \operatorname{IgD}^{+}\right)$demonstrated dosage-dependent increases in cell number upon loss of Arid 3 a ranging from 2.1-fold (control versus heterozygous $p=0.0043$ ) to 4.8 -fold (control versus homozygous $p=0.0002$ ) (Figure 1C; Figure S1B in Supplementary Material), resulting in an increase in bone marrow cellularity (Figure S1C in Supplementary Material).

$C d 79 a^{\text {Cre }}$ is well established as an efficient deleter of floxed alleles in B cells. We further confirmed this by sorting pro-B cells by fluorescence-activated cell sorting and assessing deletion of Arid $3 a$ at the mRNA level. Cells from heterozygous mice contained both wild-type and exon- 4 deleted Arid $3 a$, whereas cells sorted from homozygous mice only contained the deleted allele (Figure 1D). We further sequenced this deleted allele and confirmed that an out of frame mRNA is produced upon loss of exon 4 resulting in a protein with multiple premature stop codons (Figure S1D in Supplementary Material). In summary, loss of Arid $3 a$ leads to reductions in bone marrow B1 cell numbers and conversely a more noticeable expansion of all stages of B2 cell development.

\section{Expanded Peripheral B2 Cell Populations in Arid3a-Deficient Mice}

The expansion of $\mathrm{B}$ cell numbers in the bone marrow could result in further abnormalities in peripheral B cell numbers. We analyzed control, heterozygous, and homozygous mice at 10-12 weeks of age and quantified the absolute cell numbers of various B cell subsets in the spleen. We observed a twofold expansion $(p=0.0001)$ in B2 cell numbers in homozygous versus control mice, but no difference in B1 cell numbers. This increase in B2 cells was dosage dependent as loss of one Arid $3 a$ allele also resulted in increases in absolute numbers of B cells $(p=0.0032)$ (Figure 2A; Figure S2A in Supplementary Material), with subsequent increases in spleen cellularity and $\mathrm{CD}^{+}$cell numbers (Figures S2B,C in Supplementary Material). We next wished to determine which subset was responsible for the increase in B2 cell number. Transitional $1 \mathrm{~B}$ cells $\left(\mathrm{B} 220^{+} \mathrm{CD} 1\right.$ $\left.9^{+} \operatorname{IgM}^{+} \mathrm{CD} 23^{-}\right)$were increased in both heterozygous $(p=0.0024)$ and homozygous $(p=0.0027)$ versus control mice. Transitional 2 B cells $\left(\mathrm{B} 220^{+} \mathrm{CD} 19^{+} \mathrm{IgM}^{+} \mathrm{CD} 23^{+}\right)$were increased up to 2.4 -fold ( $p=0.0036)$ in homozygous mice versus controls (Figure 2B). An alternative gating strategy incorporating CD93 also revealed increases in immature splenic populations (Figure S2D in Supplementary Material). Similarly, the number of follicular B cells (defined $\mathrm{B} 220^{+} \mathrm{CD} 21^{+} \mathrm{CD} 21^{\mathrm{lo}} \mathrm{CD} 23^{+}$) was also increased in cell numbers and again appeared to be dosage sensitive to loss of Arid3a (control versus heterozygous $p=0.0022$ : control 


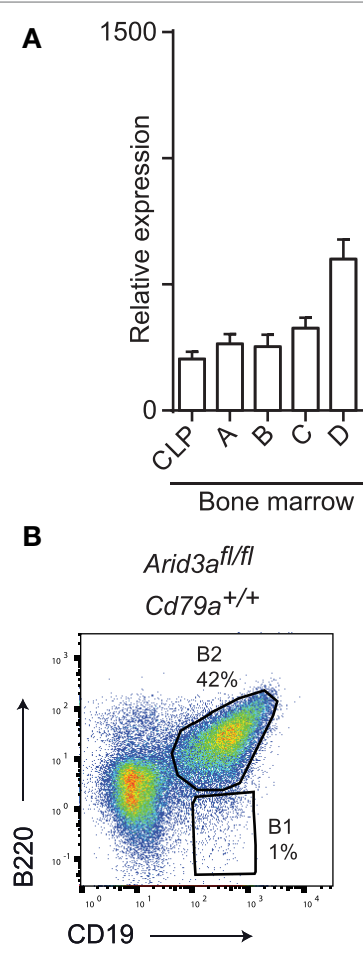

C
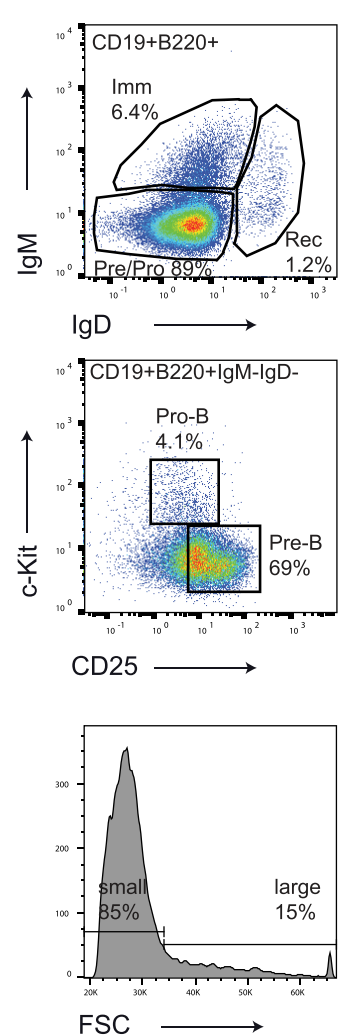


D

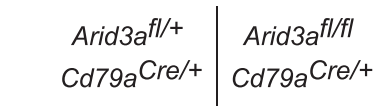

HPRT

Arid3a



WT/FI

\urcorner$_{\mathrm{DE}} 4$
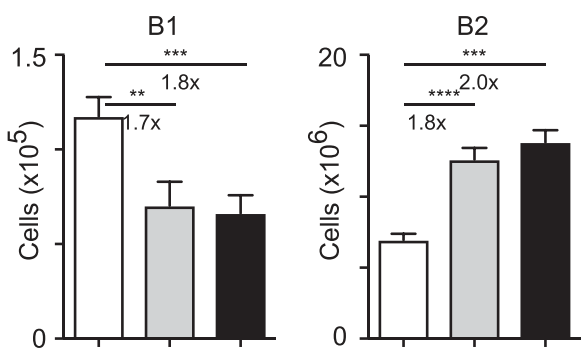

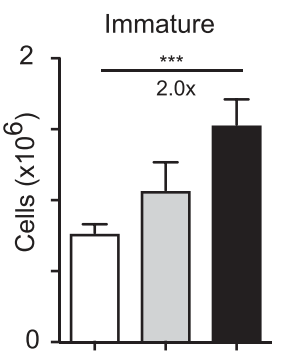

Pro-B


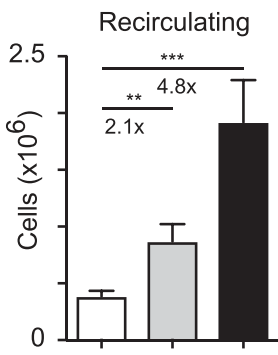

Pre-B

FIGURE 1 | Continued

Conditional loss of Arid3a and B cell development. (A) Relative expression of Arid3a in B cell subsets in the bone marrow (common lymphoid progenitor and fractions A to E), spleen (transitional and mature stages), and peritoneal cavity using data from the ImmGen database. (B,C) Flow cytometry of bone marrow B cell

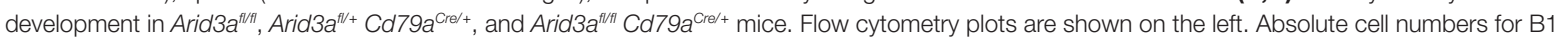

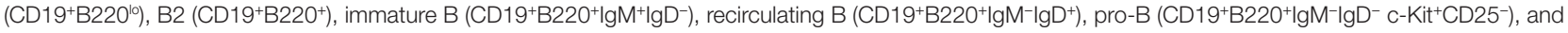
pre-B (CD19+B220+IgM-lgD- ${ }^{-}-$Kit $\left.^{-} \mathrm{CD} 25^{+}\right)$cell populations are shown on the right. Error bars represent SEM and $n=17-24$ for each group. $p$-Values were determined by Student's $t$-test and fold changes are indicated. (D) Deletion of the conditional Arid3a allele determined by RT-polymerase chain reaction in sorted

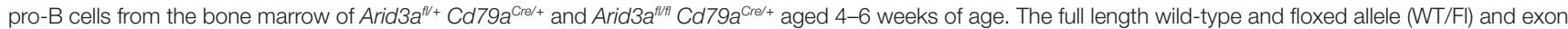
4 deleted allele $(\triangle \mathrm{E} 4)$ are indicated. $H P R T$ was used as a loading control.

versus homozygous $p<0.0001$ ). Marginal zone B cells (defined $\left.\mathrm{B} 220^{+} \mathrm{CD} 21^{+} \mathrm{CD} 21^{\mathrm{hi}} \mathrm{CD} 23^{\text {lo }}\right)$ were also increased in homozygous versus control mice ( $p=0.0095$ ) (Figure 2C). Interestingly, surface IgM levels were decreased on follicular and marginal zone $B$ cells in homozygous mice (Figure 2D). In summary, peripheral $\mathrm{B}$ cell numbers are expanded upon loss of Arid $3 a$ in similar fashion to $\mathrm{B}$ cell progenitors in the bone marrow.

\section{The In Vivo Role of Arid3a in the B1 versus B2 Cell Development}

Arid3a has recently been positioned as a key regulator of the $\mathrm{B} 1$ versus $\mathrm{B} 2$ lineage $(5,11)$. The reduction of $\mathrm{B} 1$ cells in the bone marrow indicated that this phenotype is also present upon conditional loss of Arid $3 a$ in the adult mouse. We therefore analyzed a key reservoir of B1 cells in the mouse, namely the peritoneal cavity. We observed a strong decrease in the relative abundance of $\mathrm{B} 1 \mathrm{a}\left(\mathrm{CD} 19^{+} \mathrm{B} 220^{\text {lo }} \mathrm{CD} 5 \mathrm{a}^{+}\right)$cells in homozygous mice, being 5.2-fold ( $p=0.0306)$ reduced relative to controls. B2 cells and $\mathrm{B} 1 \mathrm{~b}\left(\mathrm{CD} 19^{+} \mathrm{B} 220^{\mathrm{lo}} \mathrm{CD} 5 \mathrm{a}^{-}\right)$cells were not significantly reduced in numbers (Figure $\mathbf{3 A}$ ). These B1a cells were further confirmed to have a cell surface phenotype of $\operatorname{IgM}^{\text {hi }}, \operatorname{IgD}^{\text {lo }}$, and $\mathrm{CD}_{1} \mathrm{~b}^{+}$(Figure 3B). An alternative gating strategy to define B1 cells $\left(\mathrm{CD} 19^{+} \mathrm{CD} 11 \mathrm{~b}^{+}\right)$produced similar results (Figures $\mathrm{S} 3 \mathrm{~A}, \mathrm{~B}$ in Supplementary Material). Finally, we confirmed that peritoneal lymphocytes were deleted for Arid3a by sorting B1 and B2 cells and determining Arid $3 a$ deletion. Similar to the results from bone marrow pro-B cells, homozygous mice displayed efficient deletion of exon 4 of Arid3a (Figure 3C). We could therefore confirm that $A$ rid $3 a$ is required for normal peritoneal B1a cell development.

\section{The Function of Arid3a in Humoral Immunity}

The humoral immune response of mouse $\mathrm{B}$ cells has been reported to be influenced by the transcription factor Arid3a. We measured total plasma immunoglobulin levels in naïve mice and found significant decreases in $\operatorname{IgM}(p=0.0003), \operatorname{IgA}(p=0.039)$, and IgG $(p=0.0001)$ in homozygous mice compared to controls (Figure 4A), similar to that reported in mice expressing dominant-negative Arid3a (7) and the very rare survivor mice from the germline deleted Arid3a strain (6). Within the IgG fraction, levels of IgG1, IgG2b, and IgG3 were all significantly reduced (Figure 4B). We did not observe any significant differences in heterozygous mice relative to control mice.

A consistent feature of mice with perturbed Arid $3 a$ function is reduced antibody titers against the hapten phosphocholine, which in C57/Bl6 mice is partially dependent on $\mathrm{V}(\mathrm{D}) \mathrm{J}$ rearrangements that have incorporated $V_{H} S 107.1 .42(12,13)$. We assayed titers of IgM against phosphocholine and observed significant decreases in naïve homozygous mice versus that of controls $(p=0.0006)$ (Figure 5A). We next immunized mice with the antigen phosphocholine linked to Keyhole limpet hemocyanin (PC-KLH) emulsified in Alum to study germinal centre formation and specific $\mathrm{T}$ cell-dependent immune responses. We observed a reduction in anti-phosphocholine $\operatorname{IgM}$ responses 14 days after immunization ( $p=0.0056$ ) (Figure 5B). We next tested if this reduced anti-PC response was due to an inability to form germinal centers. Activated B cells $\left(\mathrm{CD} 19^{+} \mathrm{B} 220^{+} \mathrm{IgD}^{\mathrm{lo}} \mathrm{CD} 95^{+} \mathrm{GL}^{+}\right)$ could be readily detected in the spleen following immunization in all genotypes and were also present in normal numbers in the Peyer's patches and mesenteric lymph nodes regardless of the Arid3a genotype (Figure 5C).

\section{DISCUSSION}

The regulation of the $\mathrm{B} 1$ versus the $\mathrm{B} 2$ cell fate is thought to be controlled either through antigen receptor specificity within the immature and transitional B cell stages, as ontogenically separate lineages, or a combination of these two models (14). Several transcription factors have been shown to effect the relative abundance of B1 versus B2 cells in secondary lymphoid organs, including Ebf1 (15), classical NF-kappaB signaling (16), and most recently Bhlhe41 (17). Arid $3 a$ has also been proposed to critically regulate the B1 versus B2 cell fate (11). Using conditional mutagenesis in the adult mouse, we found no evidence that expression of Arid $3 a$ is required for the production of $\mathrm{B} 1$ lymphocytes at the expense of B2 cells in the spleen, in agreement with studies that used RAG-deficient blastocyst complementation with Arid $3 a$ germline deleted ES cells (6) and overexpression of dominantnegative form of Arid3a (7). However, we did observe a loss of Bla cells in the peritoneal cavity, indicating that Arid $3 a$ has a very specific function in the generation of peritoneal B1a lymphocytes and is possibly responsible for the reduction in the IgM titers we observed. One possibility is that Arid3a may regulate migration of Bla cells to the peritoneal cavity.

Loss of Arid3a resulted in the expansion of all the B cell developmental stages in the bone marrow. This stage specific affect mirrors the expression pattern of Arid3a. Previous analysis of the less than $1 \%$ of germline deleted Arid $3 a$ mice that survived to adulthood had indicated a possible role for this transcription factor in early B cell development (6); however, this germline-deficient strain has strong reductions in the common 


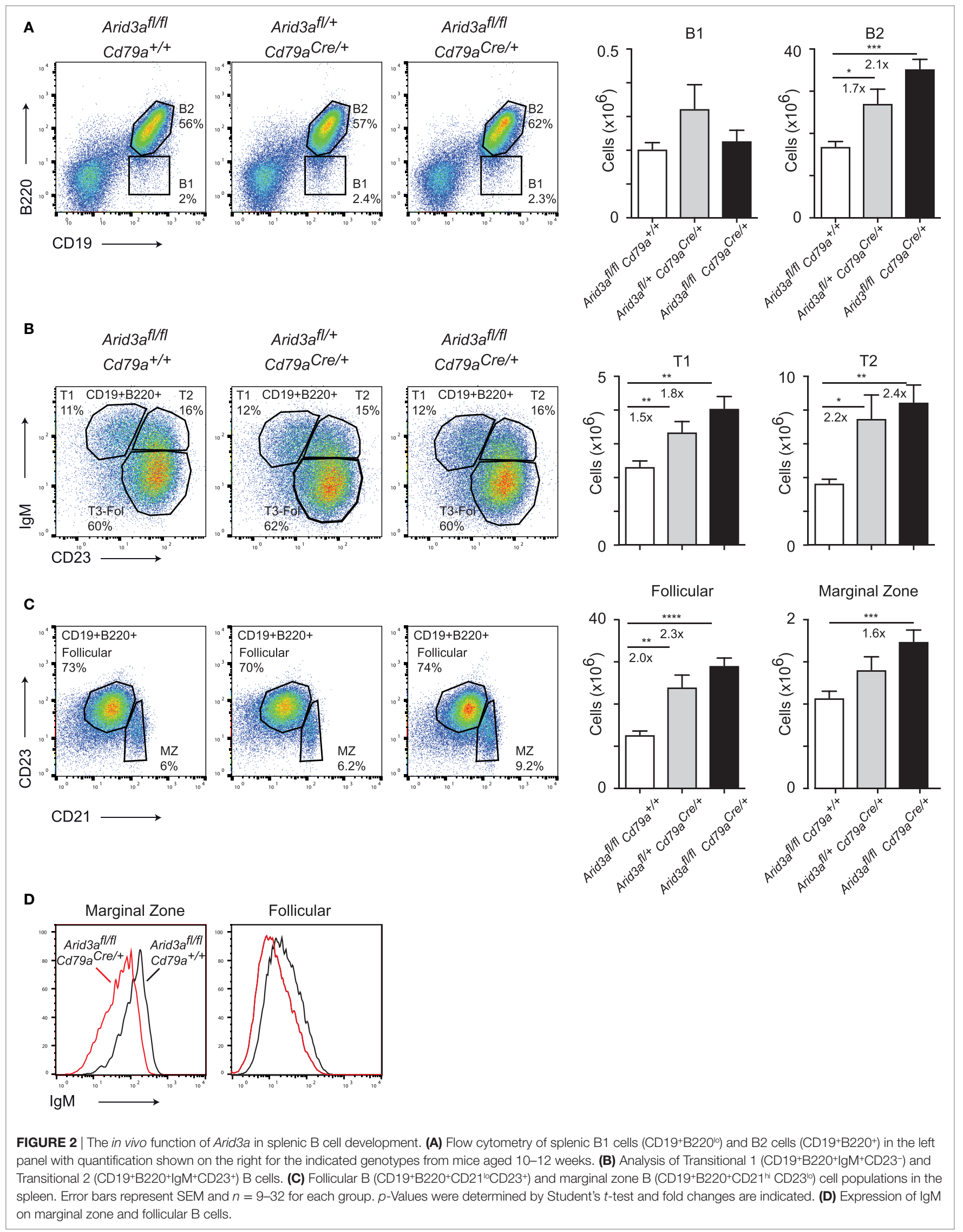


A
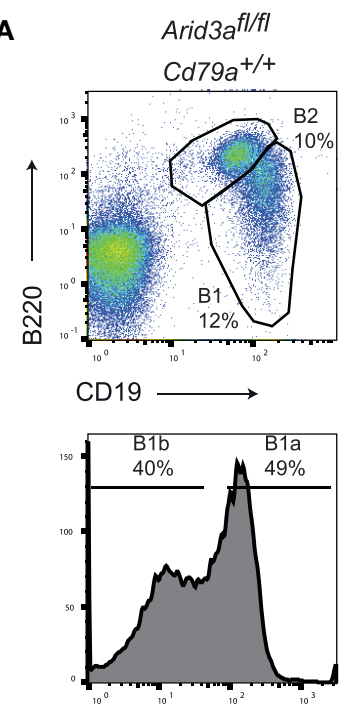

CD5 $\longrightarrow$

B

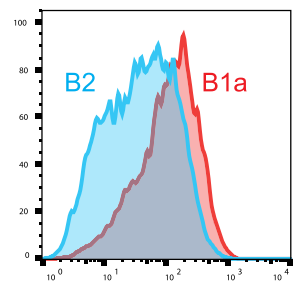

$\lg \mathrm{M} \longrightarrow$

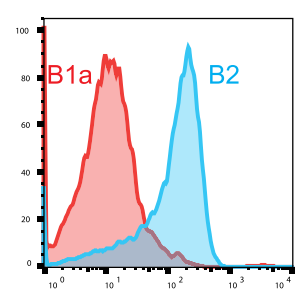

$\lg \mathrm{D} \longrightarrow$



C
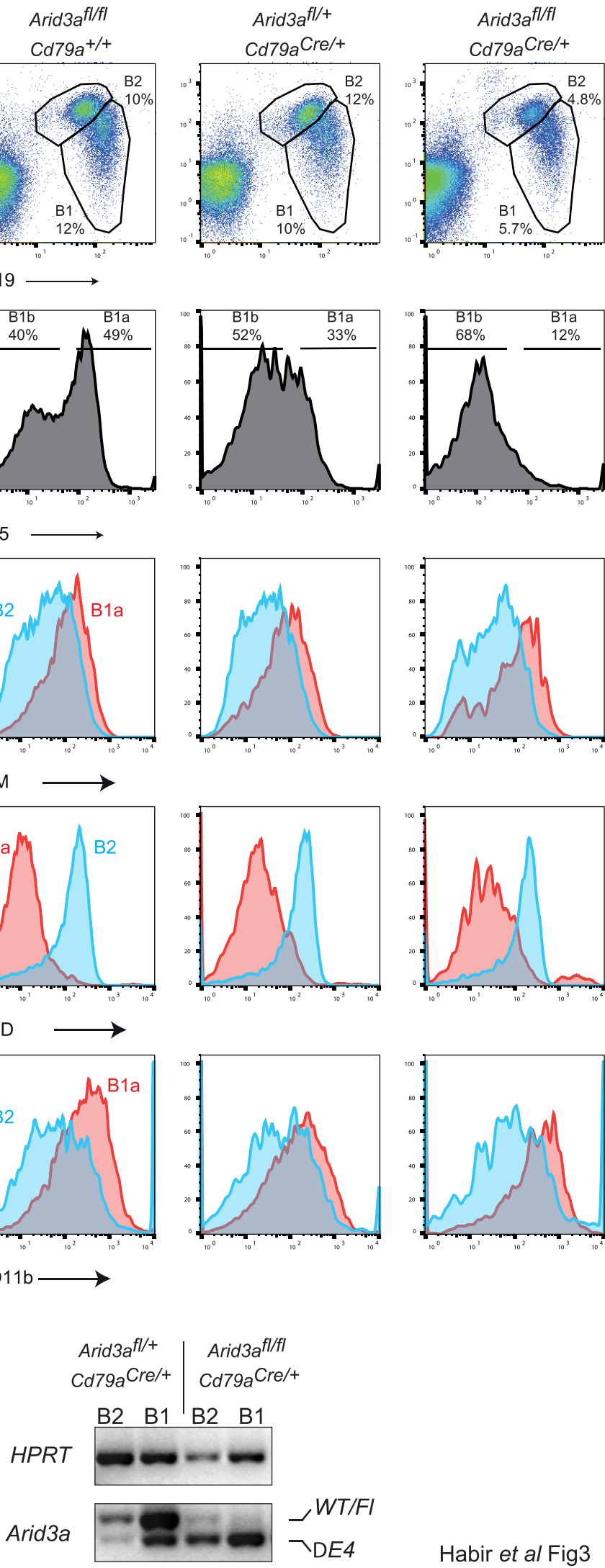

Habir et al Fig3
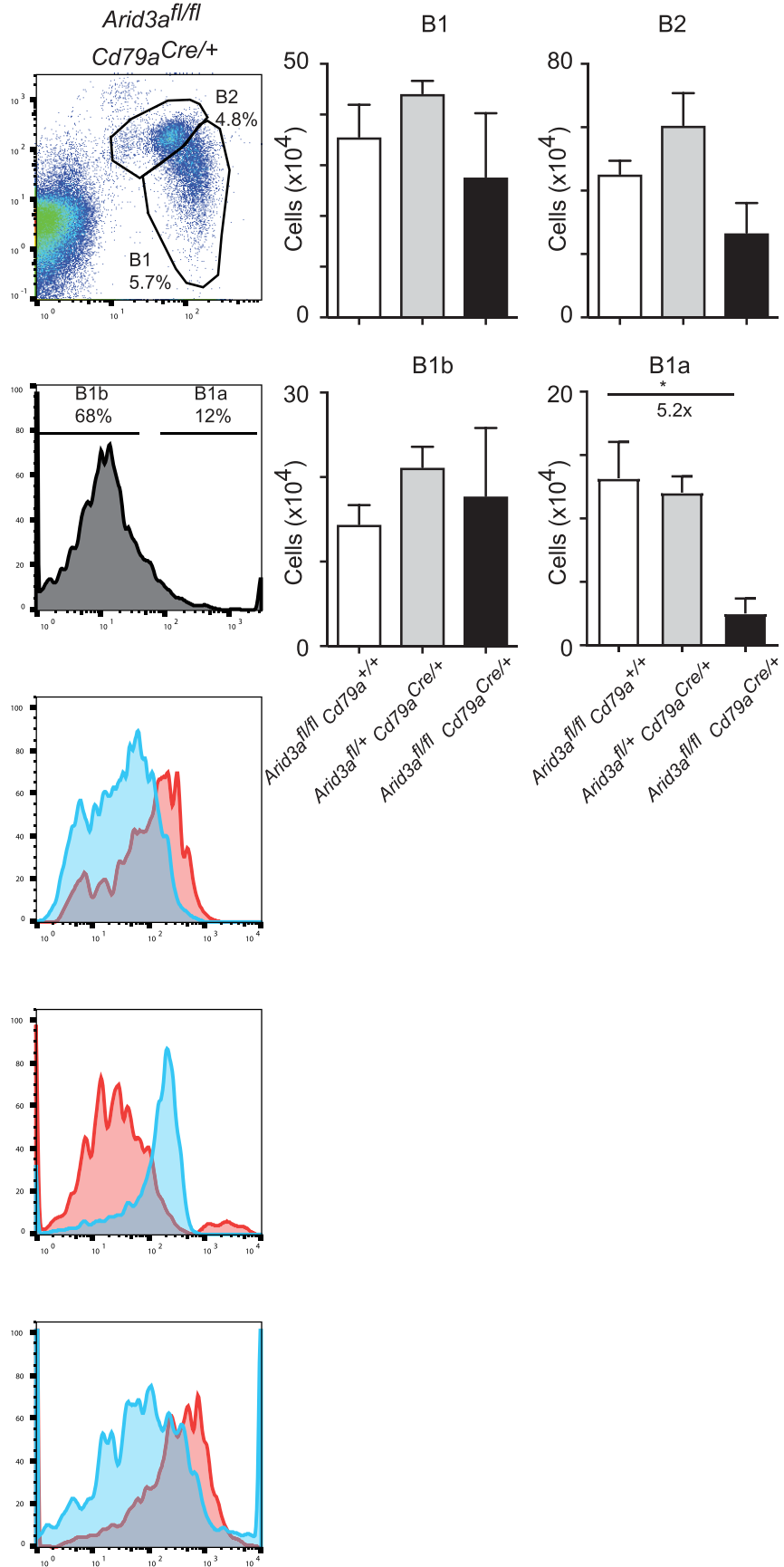
FIGURE 3 | Continued

Arid3a is required for normal peritoneal cavity B1a cell development. (A) Flow cytometry of B1 cells $\left(C D 19^{+} B 220^{\circ}\right)$ and B2 cells $\left(C D 19^{+} B 220^{+}\right)$taken from peritoneal lavages of mice aged 10-12 weeks old. B1 cells were further gated for CD5 to determine $\mathrm{B} 1 \mathrm{a}\left(\mathrm{CD} 19^{+} \mathrm{B} 22^{\circ} \mathrm{O}^{\mathrm{C}} \mathrm{CD} 5^{+}\right)$and $\mathrm{B} 1 \mathrm{~b}\left(\mathrm{CD} 19^{+} \mathrm{B} 22 \mathrm{O}^{\circ} \mathrm{CD} 5^{-}\right)$populations shown in the bottom panel. Error bars represent SEM and $n=3-8$ for each group. $p$-Values were determined by Student's $t$-test and fold changes are indicated. (B) Cell surface phenotype of B1a $\left(\mathrm{CD}_{19}{ }^{+} \mathrm{B} 22 \mathrm{O}^{\mathrm{lo}} \mathrm{CD}^{+}\right)$and B2 $\left(\mathrm{CD} 19^{+} \mathrm{B} 22 \mathrm{O}^{+}\right)$cells. (C) Deletion of the conditional Arid3a allele was shown by RT-polymerase chain reaction

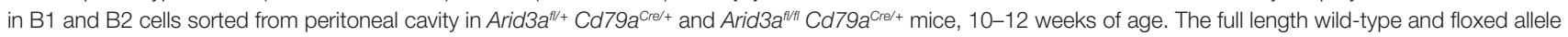
(WT/FI) and exon 4 deleted allele ( $\triangle \mathrm{E} 4)$ are indicated. HPRT was used as a loading control.


B

$\lg$ 1 1

$\lg G 2 b$
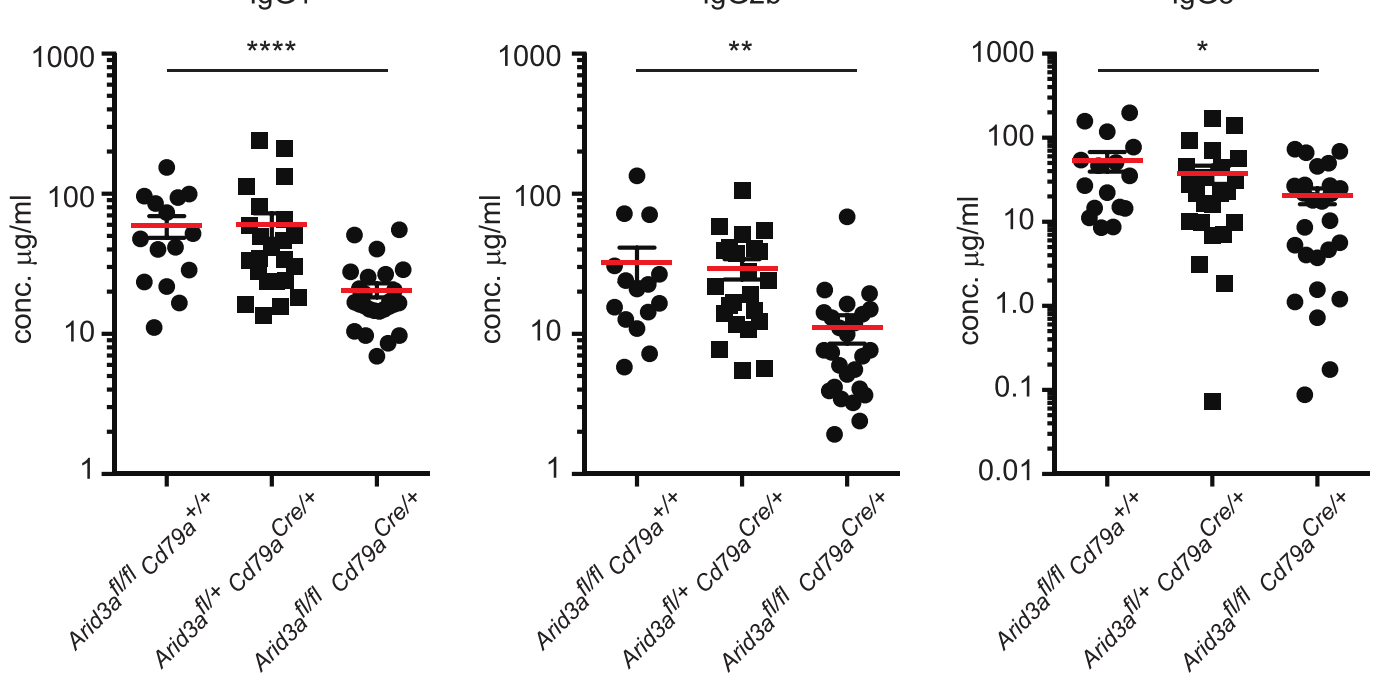

FIGURE $4 \mid$ A requirement for Arid3a in humoral immunity. (A) Plasma was collected from naive mice of the indicated genotypes aged 10-12 weeks old and analyzed for total IgM, IgA, and IgG levels with Enzyme-Linked ImmunoSorbent Assay. (B) IgG1, IgG2b, and IgG3 antibody titers. $n=15-26$ for each group and $p$-values were determined by Student's $t$-test.

lymphoid progenitor compartment. Mature B cells were generated normally from Arid $3 a^{-/-}$when using RAG-deficient blastocyst complementation, indicating that bone marrow B cell development had proceeded normally (6). Hence, the loss of B cell progenitors in Arid $3 a^{-/-}$is probably due to the profound developmental defects in hematopoietic progenitors that occur in this strain. Similar results were obtained by conditional deletion of the related Arid $3 b$ in the mouse, which also resulted in a reduction of common lymphoid progenitors (18). Interestingly, follicular B cells were also expanded in this strain. It is possible 

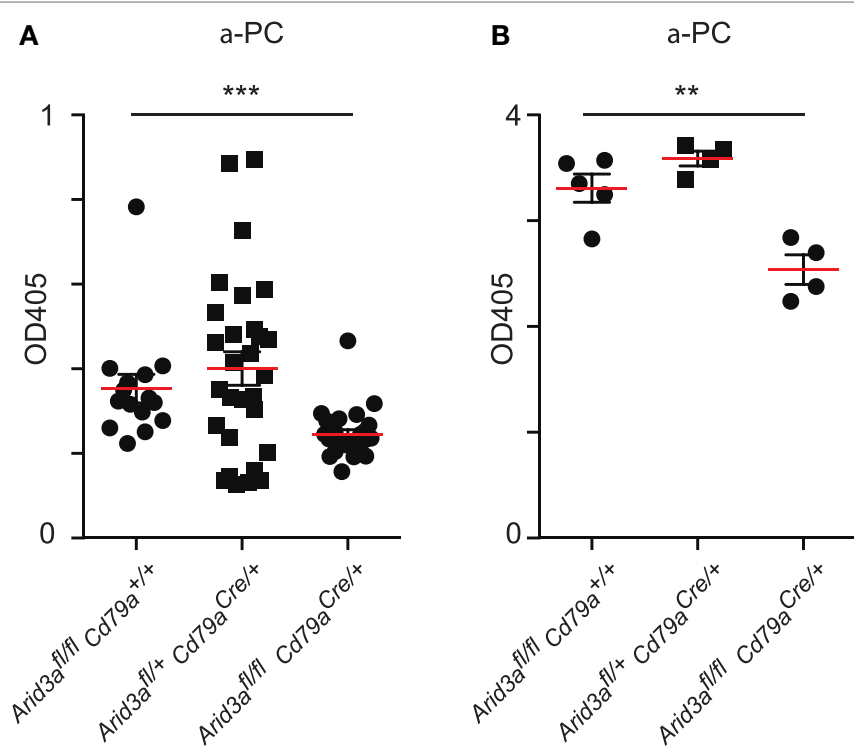

C
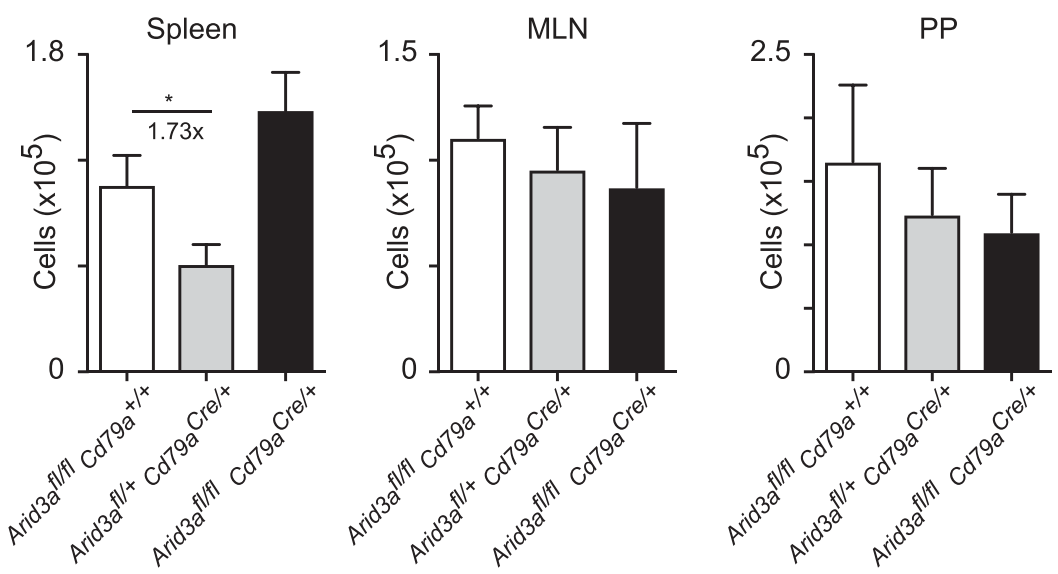

FIGURE 5 | Normal antibody production against phosphocholine requires Arid3a. (A) Enzyme-Linked ImmunoSorbent Assay measurements of anti-phosphocholine IgM in naïve mice from the indicated genotypes $n=15-28$ for each group. (B) Anti-phosphocholine lgM levels 14 days after PC-KLH immunization $n=4-5$ for each group. (C) Absolute number of cells with a germinal center phenotype (CD19+B220+lgD-GL7+CD95+) in spleen, Peyer's patches, and mesenteric lymph nodes after immunization with PC-KLH/Alum. $n=4-6$ for each group. $p$-Values determined by Student's $t$-test.

that Arid3a and Arid3b have redundant functions during B lymphopoiesis, and combined deletion of these two factors will be required to confirm this.

Although we could demonstrate that the $m R N A$ from our deleted allele should result in a missense protein, we were not able to measure ARID3A protein levels in our experiments through western blot experiments despite using multiple commercially available antibodies. We cannot therefore formally rule out that a truncated protein is produced through evasion of nonsensemediated decay. However, we note that loss of exon 4 in the highly related Arid $3 b$ deleted locus resulted in loss of this protein (18).

Heterozygous or homozygous loss of Arid3a resulted in a complex set of phenotypes. Within bone marrow B cell development, heterozygous animals had similar increases in pre-B cells as homozygous mice, whereas for pro-B, immature and recirculating cells, loss of both alleles produced a more prominent expansion.
This dosage pattern was conserved in spleen populations. This expansion of $\mathrm{B}$ cell progenitors we observed may have implications for B cell acute lymphoblastic leukemia (B-ALL). Knockdown of ARID3A in 70Z/3 and Ba/F3 B cell progenitor cell lines resulted in increased proliferation, and $A R I D 3 A$ was downregulated in a subset of B-All patients (19). Our results would be consistent with Arid3a suppressing proliferation in B cell progenitors. Alternatively, Arid3a may also have a function in cell survival. Regardless, expansion of certain B-ALL clones may be sensitive to the dosage of ARID3A, as normal B lymphopoiesis is expanded upon loss of one or two Arid3a alleles.

Loss of Arid3a results in specific defects in humoral responses, especially a partial defect in IgM responses against phosphocholine. The defects observed in immature bone marrow B cell development in Arid3a-deficient B cells may partially be the consequence of a positive feedback loop, as mice that cannot 
secrete IgM have increased immature B cells (20). Hence, in Arid3a-deleted B cells, there is diminished production of phosphocholine binding natural IgM. This is probably resulting from reduced $V_{H} S 107.1 .42$ expression, which is regulated by ARID3A (6). In contrast to bone marrow progenitors, however, the reduction in peritoneal B1a cells and plasma immunoglobulin levels was only observed in homozygous mice.

Although the defects we observed upon loss of Arid $3 a$ may appear subtle, increased ARID3A expression in human B cells correlates with the severity of systemic lupus erythematosus (21), which may be indicative of a more general function of this transcription factor in autoimmunity. The reduction in "natural" IgM against phosphocholine could make the Arid $3 a^{f / f l} \mathrm{Cd} 79 a^{\mathrm{Cre} / \mathrm{t}}$ strain useful in disease models where these natural antibodies have been implicated, for example, in SLE models and atherosclerosis.

\section{MATERIALS AND METHODS}

\section{Mice}

The Arid $3 a^{t m 1 a(K O M P) W t s i}$ allele was imported from the KOMP resource and in vitro fertilized with sperm from the B6.Cg$\mathrm{Tg}$ (ACTFLPe)9205Dym/J strain to remove the Frt flanked selection and reporter cassette to create Arid $3 a^{f l /+}$ mice. Mice were then further crossed with the $C d 79 a^{\mathrm{Cre} /+}$ strain to create control and homozygous mice. All experiments used mice at 4-6 or 10-12 weeks of age and were approved by the Stockholm Regional Board for Animal Ethics, permit numbers N46/14, N164/14, and N111/11. Mice were regularly controlled by the Swedish Veterinary Authorities.

\section{Genotyping with Polymerase Chain Reaction (PCR)}

Polymerase chain reaction was performed after DNA extraction from ear biopsies of mice. The Arid $3 a^{f / f l}$ and Arid $3 a^{f /+}$ DNA fragments were amplified with the primers: $5^{\prime}$-CTCCTTCCT CTTGTCTCCTGTGTGG-3' (ttR)and5' -TGCCTGTTGGAAGG ATGATCTGG-3' (F); and with the primers 5'-GAGATGGCGC AACGCAATTAATG-3' (loxF) and 5'-GATAGCTCAGGAGCT TCCTCACACC- $3^{\prime}$ (R). The $C d 79 a^{\text {Cre/+ }}$ fragment was amplified with the following primers: 5'-CCTTGCGAGGTCAGGGAGCC-3' (WT reverse), 5'-GTCCTGGCATCTGTCAGAG-3' (Cre reverse) and 5'-GGCTCTGACCCATCTGTCTC-3' (common forward). Primers ttR and F amplified a 354-bp wild-type fragment and a 470-bp postFlp fragment. Primers loxF and R amplified a 253bp floxed fragment. Primers WT reverse and common forward gave a 477-bp wild-type fragment, and primers Cre reverse and common forward gave a 500-bp $C d 79 a^{\text {Cre/ }}$ specific product. PCR products were subsequently separated by electrophoresis through agarose gels and visualized by GelRed nucleic acid gel stain (Biotium).

\section{Flow Cytometry}

Bone marrow from Femur and Tibia of the two hind legs of 4-6 weeks old mice, and spleen and peritoneal cavity from 10 to 12 weeks old mice was isolated. Tissues were then fractioned to single-cell suspensions and filtered through $100-\mu \mathrm{m}$ cell strainers
(Sigma-Aldrich) with phosphate-buffered saline (PBS) containing $0.5 \%$ fetal bovine serum (FBS). Erythrocytes were thereafter lysed with Ammonium-Chloride-Potassium Lysing Buffer. Single-cell suspensions of bone marrow, spleen, and peritoneal cavity were pre-incubated at a density of $100 \times 10^{6}$ cells $/ \mathrm{ml}$ with Fc Block (BD Biosciences), and cells were subsequently analyzed by a CyAn ADP (Beckman Coulter) flow cytometer with the following antibodies B220 (APC-Cy7 clone: RA3-6B2), anti-CD19 (Alexa Fluor 647 clone: eBio1D3), anti-CD25 (PE-Cy7 clone: PC61.5), anti-c-kit (PE clone: 2B8), anti-CD5 (PE clone: 53-7.3), anti-GL7 (APC clone: GL-7), anti-CD95 (PE-Cy7 clone: Jo2), anti-IgD (PerCP clone: 11-26c.2a), anti-IgM (Pacific Blue clone: Il/41), anti-CD23 (PE-Cy7 clone: B3B4), anti-CD21 (FITC clone: 7G6), and anti-CD11b (PerCPclone: M1/70). Immune cell populations were defined as follows: B-1 $\left(\mathrm{CD} 19^{+} \mathrm{B} 220^{\mathrm{lo}}\right)$ or $\left(\mathrm{CD} 19^{+} \mathrm{CD} 11 \mathrm{~b}^{+}\right)$, B-1a $\left(\mathrm{CD} 19^{+} \mathrm{B} 220 \mathrm{loCD}^{+}\right)$or $\left(\mathrm{CD} 19^{+} \mathrm{CD} 11 \mathrm{~b}^{+} \mathrm{CD} 5^{+}\right), \mathrm{B}-1 \mathrm{~b}$

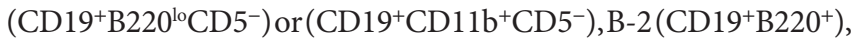
pro-B $\left(\mathrm{CD} 19^{+} \mathrm{B} 220^{+} \mathrm{IgM}^{-} \mathrm{IgD}^{-} \mathrm{c}-\mathrm{Kit}^{+} \mathrm{CD} 25^{-}\right)$, pre-B $\left(\mathrm{CD} 19^{+} \mathrm{B} 220^{+}\right.$ $\left.\mathrm{IgM}^{-} \operatorname{IgD}^{-} \mathrm{C}-\mathrm{Kit}^{-} \mathrm{CD} 25^{+}\right)$, immature-B cells $\left(\mathrm{CD} 19^{+} \mathrm{B} 220^{+} \mathrm{IgM}^{+} \operatorname{IgD}^{-}\right)$ recirculating-B cells $\left(\mathrm{CD}^{-} 9^{+} \mathrm{B} 220^{+} \mathrm{IgM}^{-} \mathrm{IgD}^{+}\right)$, Transitional-1 $\left(\mathrm{CD} 19^{+} \mathrm{B} 220^{+} \mathrm{IgM}^{+} \mathrm{CD} 23^{-}\right)$or $\left(\mathrm{CD} 19^{+} \mathrm{B} 220^{+} \mathrm{CD}^{+} 3^{+} \mathrm{IgM}^{+} \mathrm{CD} 23^{-}\right)$, Transitional-2 $\left(\mathrm{CD} 19^{+} \mathrm{B} 220^{+} \mathrm{IgM}^{+} \mathrm{CD} 23^{+}\right)$or $\left(\mathrm{CD} 19^{+} \mathrm{B} 220^{+} \mathrm{CD} 93^{+}\right.$ $\left.\operatorname{IgM}^{+} \mathrm{CD} 23^{+}\right)$, marginal zone B cells $\left(\mathrm{CD} 19^{+} \mathrm{B} 220^{+} \mathrm{CD} 21^{\mathrm{hi}} \mathrm{CD} 23^{\mathrm{lo}}\right)$, follicular B cells $\left(\mathrm{CD} 19^{+} \mathrm{B} 220^{+} \mathrm{CD} 21^{\text {int }} \mathrm{CD} 23^{\text {hi }}\right)$ germinal center $\mathrm{B}$ cells $\left(\mathrm{CD} 19^{+} \mathrm{B} 220^{+} \mathrm{IgD}^{-} \mathrm{GL}^{+} \mathrm{CD}^{+} 5^{+}\right)$. Absolute cell numbers were calculated by first counting live cells using a BioRad TC-20 cell counter based on trypan blue exclusion. Cells within a defined gated quadrant were divided by the cells contained in a large gate encompassing all live cells and excluding debris as determined by forward and side scatter properties from the flow cytometry. This ratio was then multiplied by the cell count to give the absolute cell number.

\section{Cell Sorting and Deletion Analysis}

Pro-B cells from bone marrow and B1 and B2 peritoneal cavity cells of Arid $3 a^{f / /+} C d 79 a^{C r e /+}$ and Arid $3 a^{f l / f l} C d 79 a^{C r e /+}$ mice were sorted into PBS containing 0.5\% FBS before RNA extraction with the RNeasy Mini Kit (Qiagen). cDNA was synthesized with High capacity RNA-to-cDNA Kit (Applied Biosystems) followed by PCR with primers with the following Arid3a oligonucleotides: 5'-TGGACCTTTGAGGAGCAGTT-3' (Primer 1) and 5'-GATGGAGGTAGGCAGGTTGA-3' (Primer 2). A 255-bp PCR product was amplified from the floxed Arid3a allele and a 182-bp product from the deleted Arid3a allele. The Hypoxanthine guanine phosphoribosyl transferase (HPRT) gene was used as a control with primers GGGGGCTATAAGTTCTTTGC and TCCAACACTTCGAGAGGTCC generating a 312-bp PCR product. PCR products were then separated by electrophoresis through agarose gels and visualized by GelRed nucleic acid gel stain.

\section{Immunization and Enzyme-Linked ImmunoSorbent Assay (ELISA)}

For immunization with PC-KLH (Biosearch Technologies Inc.), $100 \mu \mathrm{g}$ of PC-KLH was precipitated on Alum and subsequently injected intraperitoneally in mice. Spleens were analyzed by flow cytometry 14 days after immunization. Specific IgM responses 
against PC-KLH was determined by ELISA using plates coated with PC-BSA (Biosearch Technologies), alkaline phosphatase coupled goat anti-mouse IgM (Southern Biotechnology Associates), and alkaline phosphatase yellow Liquid Substrate (Sigma-Aldrich). Purified rat anti-mouse IgG $(\mathrm{H}+\mathrm{L})$ (SigmaAldrich) was used as capture antibody to measure total plasma IgM, IgA, and IgG levels. AP-labeled goat anti-mouse IgM, IgA and IgG, IgG1, IgG2b, and IgG3 (Sigma-Aldrich) was used for detection.

\section{Statistical Analysis}

Data were analyzed using GraphPad Prism. p-Values of $<0.05$ from Student's $t$-tests were reported.

\section{ETHICS STATEMENT}

All experiments were approved by the Stockholm Regional Board for Animal Ethics, permit numbers N46/14, N164/14, and N111/11. Mice were regularly controlled by the Swedish Veterinary Authorities.

\section{AUTHOR CONTRIBUTIONS}

KH performed most of the experiments. SA assisted with ELISA measurements. FW provided mouse lines and contributed to the planning of the experiments. SM devised the study, interpreted data and wrote the manuscript with contributions from all authors.

\section{ACKNOWLEDGMENTS}

We thank Michael Reth and Meinrad Busslinger for providing the $C d 79 a^{C r e /+}$ strain. This research was supported by the Swedish Medical Research Council (Vetenskapsrådet) to the Linné Center

\section{REFERENCES}

1. Kantor A. A new nomenclature for B cells. Immunol Today (1991) 12:388. doi:10.1016/0167-5699(91)90135-G

2. Yuan J, Nguyen CK, Liu X, Kanellopoulou C, Muljo SA. Lin28b reprograms adult bone marrow hematopoietic progenitors to mediate fetal-like lymphopoiesis. Science (2012) 335:1195. doi:10.1126/science.1216557

3. Das C, Eaton S, Calame K, Tucker PW. Novel protein-DNA interactions associated with increased immunoglobulin transcription in response to antigen plus interleukin-5. Mol Cell Biol (1991) 11:5197. doi:10.1128/MCB.11. 10.5197

4. Herrscher RF, Kaplan MH, Lelsz DL, Das C, Scheuermann R, Tucker PW. The immunoglobulin heavy-chain matrix-associating regions are bound by Bright: a B cell-specific trans-activator that describes a new DNA-binding protein family. Genes Dev (1995) 9:3067. doi:10.1101/gad.9.24.3067

5. Zhou Y, Li YS, Bandi SR, Tang L, Shinton SA, Hayakawa K, et al. Lin28b promotes fetal B lymphopoiesis through the transcription factor Arid3a. J Exp Med (2015) 212:569-80. doi:10.1084/jem.20141510

6. Webb CF, Bryant J, Popowski M, Allred L, Kim D, Harriss J, et al. The ARID family transcription factor bright is required for both hematopoietic stem cell and B lineage development. Mol Cell Biol (2011) 31:1041-53. doi:10.1128/ MCB.01448-10

7. Nixon JC, Ferrell S, Miner C, Oldham AL, Hochgeschwender U, Webb CF. Transgenic mice expressing dominant-negative bright exhibit defects in B1 B cells. J Immunol (2008) 181:6913. doi:10.4049/jimmunol.181.10.6913
CERIC (Center of Excellence for Research on Inflammation and Cardiovascular disease), the EU FP7-Health-2013-innovation-1 programme Athero-B-Cell.

\section{SUPPLEMENTARY MATERIAL}

The Supplementary Material for this article can be found online at http://www.frontiersin.org/article/10.3389/fimmu.2017.01387/ full\#supplementary-material.

FIGURE S1 | Schematic of the targeted Arid3a locus and bone marrow flow cytometry. (A) The Frt flanked Neo/LacZ cassette was removed through FLPE-mediated excision to create an allele that contains LoxP sites flanking exon 4. Exon 4 partially encodes for the DNA-binding domain and loss of this exon results in an out of frame allele. (B) Expanded bone marrow flow cytometry gating strategy. (C) Absolute numbers of live bone marrow cells. Error bars represent SEM and $n=23-36$ for each group. $p$-Values were determined by Student's $t$-test and fold changes are indicated. (D) Sequence of the wild-type and deleted Arid3a locus across exons 3-5 with the translated sequence underneath. The nonsense protein predicted from the exon 4 deleted Arid3a was confirmed by sequencing of the $m R N A$.

FIGURE S2 | Expanded flow cytometry analysis of the spleen. (A) An example of an expanded flow cytometry gating strategy for splenic B cells, indicating lymphocyte and large gates. (B) Absolute numbers of live splenic cells. Error bars represent SEM and $n=9-33$ for each group. $p$-Values were determined by Student's $t$-test and fold changes are indicated. (C) Absolute numbers of splenic $\mathrm{CD}^{+}$cells. $n=8-15$ for each group. (D) Absolute cell numbers of transitional $\mathrm{B}$ cells gated as Immature $\left(\mathrm{CD} 19^{+} \mathrm{B} 22 \mathrm{O}^{+} \mathrm{CD} 93^{+}\right), \mathrm{T} 1$

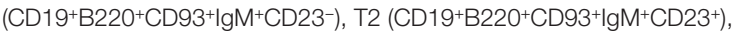
and T3 (CD19+B220+CD93+lgM $\left.{ }^{\circ}{ }^{\circ} \mathrm{CD}^{+} 3^{+}\right) . n=9-15$ for each group.

FIGURE S3 | Alternative gating analysis for peritoneal cavity B1 cells. (A) Flow cytometry of $\mathrm{B} 1$ cells $\left(\mathrm{CD} 19^{+} \mathrm{CD} 11 \mathrm{~b}^{+}\right)$taken from peritoneal lavages of mice aged 10-12 weeks old, gated for CD5, to determine B1a (CD19+CD11b+CD5+) and B1b $\left(\mathrm{CD} 19^{+} \mathrm{B} 220^{\circ} \mathrm{CD} 5^{-}\right)$populations. Error bars represent SEM and $n=3-8$ for each group. $p$-Values were determined by Student's $t$-test and fold changes are indicated. (B) Cell surface phenotype of B1a $\left(\mathrm{CD} 19^{+} \mathrm{CD} 11 \mathrm{~b}^{+} \mathrm{CD} 5^{+}\right)$and $\mathrm{B} 2$ cells $\left(\right.$ CD19+CD11 $\left.{ }^{+}\right)$.

8. Webb CF, Smith EA, Medina KL, Buchanan KL, Smithson G, Dou SS Expression of bright at two distinct stages of B lymphocyte development. J Immunol (1998) 160:4747-54.

9. Heng TS, Painter MW; Immunological Genome Project Consortium. The Immunological Genome Project: networks of gene expression in immune cells. Nat Immunol (2008) 9:1091-4. doi:10.1038/ni1008-1091

10. Hobeika E, Thiemann S, Storch B, Jumaa H, Nielsen PJ, Pelanda R, et al. Testing gene function early in the B cell lineage in mb1-cre mice. Proc Natl Acad Sci U S A (2006) 103:13789-94. doi:10.1073/pnas.0605944103

11. Li Y-S, Zhou Y, Tang L, Shinton SA, Hayakawa K, Hardy RR. A developmental switch between fetal and adult B lymphopoiesis. Ann N Y Acad Sci (2015) 1362:8-15. doi:10.1111/nyas.12769

12. Centa M, Gruber S, Nilsson D, Polyzos KA, Johansson DK, Hansson GK, et al. Atherosclerosis susceptibility in mice is independent of the V1 immunoglobulin heavy chain gene. Arterioscler Thromb Vasc Biol (2016) 36(1):25-36. doi:10.1161/ATVBAHA.115.305990

13. Mi QS, Zhou L, Schulze DH, Fischer RT, Lustig A, Rezanka LJ, et al. Highly reduced protection against Streptococcus pneumoniae after deletion of a single heavy chain gene in mouse. Proc Natl Acad Sci U S A (2000) 97:6031-6. doi:10.1073/pnas.110039497

14. Rajewsky K. The Herzenberg lecture: how to make a B-1 cell? Ann N Y Acad Sci (2015) 1362:6. doi:10.1111/nyas.12767

15. Vilagos B, Hoffmann M, Souabni A, Sun Q, Werner B, Medvedovic J, et al. Essential role of EBF1 in the generation and function of distinct mature B cell types. J Exp Med (2012) 209:775-92. doi:10.1084/jem.20112422 
16. Ádori M, Hedestam G. NF-kB signaling in B-1 cell development. Ann N Y Acad Sci (2015) 1362:39. doi:10.1111/nyas.12800

17. Kreslavsky T, Vilagos B, Tagoh H, Poliakova DK, Schwickert TA, Wöhner M, et al. Essential role for the transcription factor Bhlhe41 in regulating the development, self-renewal and BCR repertoire of B-1a cells. Nat Immunol (2017) 18:442-55. doi:10.1038/ni.3694

18. Kurkewich JL, Klopfenstein N, Hallas WM, Wood C, Sattler RA, Das C, et al. Arid3b is critical for B lymphocyte development. PLoS One (2016) 11:e0161468. doi:10.1371/journal.pone.0161468

19. Puissegur MP, Eichner R, Quelen C, Coyaud E, Mari B, Lebrigand K, et al. B-cell regulator of immunoglobulin heavy-chain transcription (Bright)/ ARID3a is a direct target of the oncomir microRNA-125b in progenitor B-cells. Leukemia (2012) 26:2224-32. doi:10.1038/leu.2012.95

20. Boes M, Esau C, Fischer MB, Schmidt T, Carroll M, Chen J. Enhanced B-1 cell development, but impaired IgG antibody responses in mice deficient in secreted IgM. J Immunol (1998) 160:4776-87.
21. James JA, Merrill JT, Webb CF. Disease activity in systemic lupus erythematosus correlates with expression of the transcription factor AT-rich-interactive domain 3A. Arthritis Rheumatol (2014) 66(12):3404-12. doi:10.1002/ art.38857

Conflict of Interest Statement: The authors declare that the research was conducted in the absence of any commercial or financial relationships that could be construed as a potential conflict of interest.

Copyright $\odot 2017$ Habir, Aeinehband, Wermeling and Malin. This is an open-access article distributed under the terms of the Creative Commons Attribution License (CC BY). The use, distribution or reproduction in other forums is permitted, provided the original author(s) or licensor are credited and that the original publication in this journal is cited, in accordance with accepted academic practice. No use, distribution or reproduction is permitted which does not comply with these terms. 